\title{
Seismic anisotropy beneath the Chinese mainland*
}

\author{
Yuanyuan V. Fu ${ }^{1, \uparrow}$ Yongshun John Chen ${ }^{2}$ and Aibing $\mathrm{Li}^{1}$ \\ ${ }^{1}$ Department of Geosciences, University of Houston, TX 77204, USA \\ ${ }^{2}$ Department of Geophysics, School of Earth and Space Sciences, Peking University, Beijing 100871, China
}

\begin{abstract}
We investigated the upper mantle anisotropy beneath China by applying teleseismic shear wave splitting measurements at 119 seismic stations from CDSN and GSN/IRIS networks in China. The splitting observations are characterized by apparent diversity of anisotropy pattern in adjacent tectonic domains, including the Tianshan orogenic belt, Tibetan plateau, the Yangtze craton, the North China craton and northeastern region. In western China (Tianshan orogenic belt and Tibetan plateau), fast polarization directions of split SKS waves coincide strikingly well with the dominating trend of deformational crustal features and delay times range from $0.5 \mathrm{~s}$ to $1.6 \mathrm{~s}$. While in eastern China, seismic anisotropy deduced from shear wave splitting reveals a homogeneous NW-SE trending structure, almost perpendicular to the strike of large-scale surface structures. The observed delay times of $1.5 \mathrm{~s}$ to more than $2 \mathrm{~s}$ favor consistent mantle flow over large mantle thicknesses. Based upon the straightforward relationships between seismic anisotropy and the development of lattice preferred orientation of mineral in upper mantle rocks, we interpret the splitting results in terms of tectonic fabric within the upper mantle. Since the lithosphere is less than $100 \mathrm{~km}$ thick beneath eastern China and the observed fast directions are subparallel to the trend of the absolute plate motion (APM) of Eurasian plate, we propose that the asthenosphere may mainly contribute to the anisotropic effects beneath eastern China. However, the upper mantle anisotropy beneath western China may have developed more recently in the subcrustal lithosphere because of rather small delay times and thick lithosphere. We also use the opportunity of the dense geodetic measurements available in China to discuss the coupling between the crust and mantle. In the Eurasia-fixed reference frame, GPS and shear wave splitting both depict a similar trend beneath eastern China, suggesting a lithospheric block "escaping" toward the east that could orient olivine [001] axis in the upper mantle. There is a strong coupling between the crust and the mantle in eastern China. A different behavior is observed in western China. The GPS vectors trend NS-NE in Tibet and NW in Tianshan, close to the regional compression direction, whereas the fast directions trend EW in Tibet and NE in Tianshan, suggesting a tectonic regime close to a mode of axial shortening, generating the development of EW-trending foliation in Tibet and NE-trending foliation in Tianshan at depth. The crust and mantle deform independently in western China.
\end{abstract}

Key words: China; shear wave splitting; seismic anisotropy; GPS

CLC number: P315.2 Document code: A

\section{Introduction}

The analysis of seismic anisotropy has been extensively developed over the last decade to emerge as a powerful tool for studying structure in the upper mantle. The anisotropic parameters are assumed to be closely related to the crystallographic fabrics developed in the upper mantle due to past and present deformation. Under uniaxial compression, the [100] axis of olivine in the

\footnotetext{
* Received 2 September 2010; accepted in revised form 8 November 2010; published 10 December 2010.

^ Corresponding author. e-mail: cugfyy@163.com

(C) The Seismological Society of China and Springer-Verlag Berlin Heidelberg 2010
}

upper mantle, along which seismic S waves have the highest propagating velocity, rotates to be perpendicular to the maximum compressional strain direction; under pure shear, it is perpendicular to the shortening direction; and under progressive simple shear, it is along the flow direction (Silver and Chan, 1991). Comparison of shear wave polarization anisotropy from core phases and surface geology can provide insights into the mechanical coupling between the crust and the upper mantle.

Upper mantle seismic anisotropy is measured from the Earth's surface by using the splitting of teleseismic shear waves. Two anisotropy parameters can be retrieved from three-component seismic records: the difference in arrival time between the two split shear waves, 
which depends on the thickness and on the intrinsic anisotropy of medium, and the azimuth of fast split wave polarization planes, which is related to the orientation of the penetrative anisotropic structure.

China, located at the southeastern corner of the Eurasian plate, is an ideal place to study the deformation pattern of the upper mantle beneath continent. From the Late Mesozoic to Cenozoic, China went through multiple episodes of significant tectonic activities characterized by uplift of Tibetan plateau and Tianshan in western China, basin-range extension and volcanism in eastern China. What dominated the tectonic activation and how the upper mantle deformed in response to those tectonic activities during the Late Mesozoic to Cenozoic are still controversial.

Three distinct mechanisms have been used to explain the uplift of the Tibetan plateau: (1) underthrusting of the Indian lithosphere, with a relatively complete crustal section, beneath the Himalayas and Tibet (e.g., Argand, 1924; Powell and Conaghan, 1973; Ni and Barazangi, 1984); (2) occurrence of crustal thickening by thickening of the southern Asian lithosphere and perhaps subsequent removal of thickened lithosphere by convective flow (Dewey and Burke, 1973; Houseman et al., 1981; England and Houseman, 1986; Molnar, 1988; Molnar et al., 1993); and (3) injection of the Indian crust into the Asian crust with subduction of the Indian continental lithosphere (Zhao and Morgan, 1987). Two major groups of models have been proposed to explain the cause and tectonic mechanism of the reactivation of eastern China. The first group proposed an extensional tectonic rejuvenation that dominated the evolution of eastern China and resulted in a dramatic transition from E-W to NE-SW striking of the major tectonic unit in eastern China. Some authors proposed that the ancient lithospheric mantle was totally or partially replaced by juvenile material in the Late Mesozoic (Wu et al., 2005), while other authors attributed the tectonic reactivation to an upwelling mantle plume or a regional asthenospheric flow (Liu, 1987; Fan and Menzies, 1992). The second group preferred that the lateral mantle flow induced by the collision and subsequent penetration of the India plate into the Eurasia plate was responsible for the upper mantle modification in North China or eastern China during the Cenozoic (e.g., Menzies et al., 1993; Niu, 2005).

New constraints are needed to test and distinguish between these competitive models. Constraints on anisotropic structure beneath China have the potential to elucidate upper mantle deformation beneath the region. Previous studies of shear wave splitting in China can be divided into two groups. Some (e.g., Vinnik et al., 1992; Ding and Zeng, 1996; Sandvol et al., 1997; Chang et al., 2006; Zhao et al., 2007; Fu et al., 2008) just focused on part region of China. While the other studied the whole China but with a few stations (e.g., Zheng and Gao, 1994; Luo et al., 2004). In the present paper, we use much more data than ever before to study the seismic anisotropy in whole China. After a description of the shear wave splitting measurements, we discuss the various possible origins of anisotropy (in the lithosphere and in the asthenosphere) in the light of independent geological and geophysical data and the current tectonic processes.

Data have been recorded at 75 permanent seismic stations maintained by Chinese Digital Seismic Network (CDSN) among which 48 are from the national network and others are from the regional network. For completeness sake, we also used data from 44 temporary broadband stations which are from G, IC, II, IU, KZ, TW, $\mathrm{XA}, \mathrm{XE}, \mathrm{XG}, \mathrm{XI}, \mathrm{XL}, \mathrm{XM}, \mathrm{XR}, \mathrm{XW}$, YA and YL networks (Figure 1). Data recorded at those national permanent stations have already been processed and have been the object of several papers. The purpose of the present study was therefore not to have a look at those data again, but rather to consider data recorded by all stations, covering the entirety of the continent, to see whether the huge amount of data available would help solve for the source location of the anisotropy measured at the surface. We selected data for national CDSN network from January 2000 to December 2005; July 2004 to December 2005 for regional CDSN network. Most of the temporary deployments had a time span of one year, since they were mainly aimed at recording events to be used for surface and body waves tomography as well as receiver function studies. The data set consists of about 4600 three-component teleseismic recordings with epicentral distance from $85^{\circ}$ to $150^{\circ}$. All the data were band-pass filtered from $0.02 \mathrm{~Hz}$ to $1 \mathrm{~Hz}$. Distribution of the events used is shown in Figure 2.

\section{Method}

Shear wave splitting measurements have been performed using Silver and Chan (1991) algorithm, which consists of minimizing the energy on the transverse component by rotating and time shifting the traces. The energy on the transverse component is automatically 


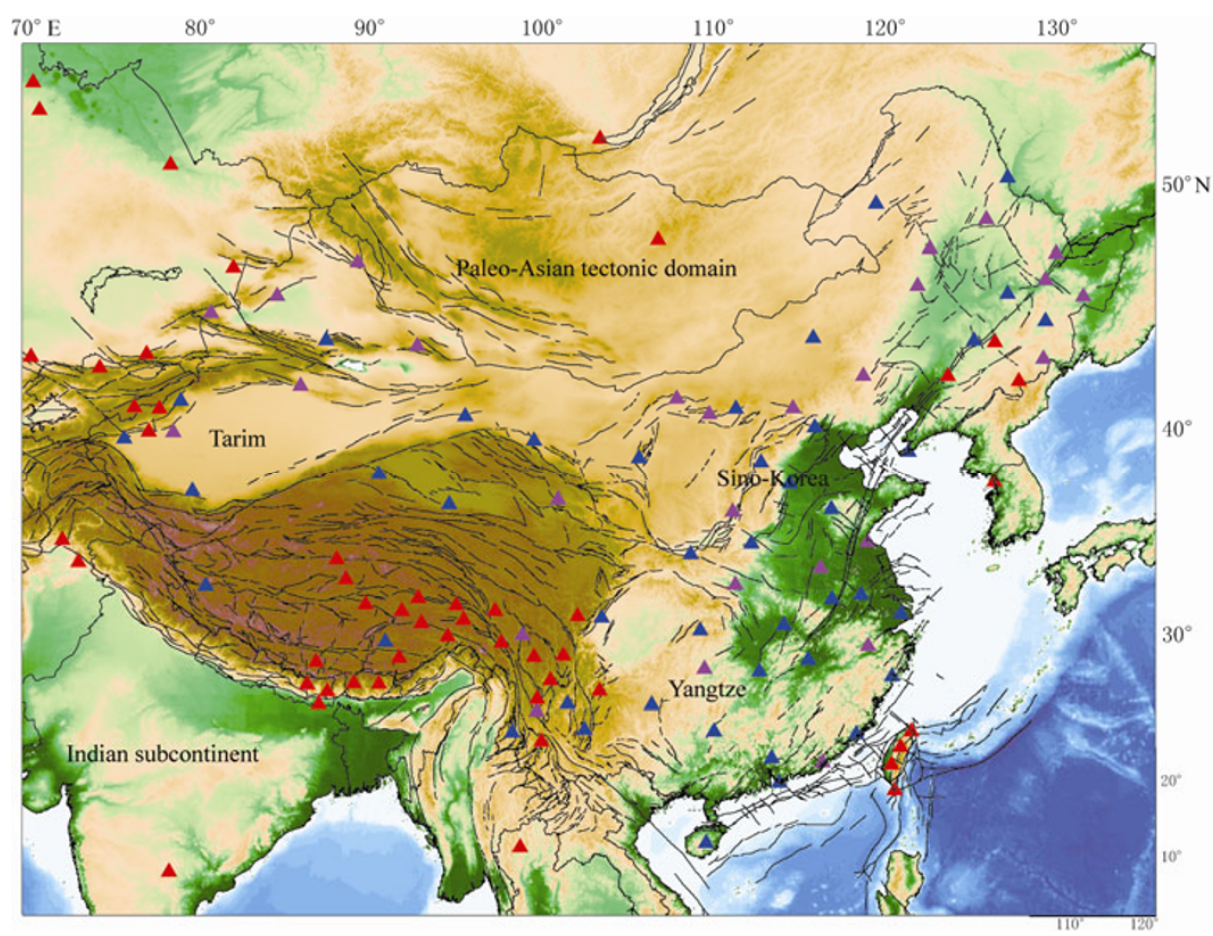

Figure 1 Location of the seismic stations used in this study. National CDSN stations are indicated by blue triangles, regional CDSN stations by purple triangles whereas temporary stations by red triangles.

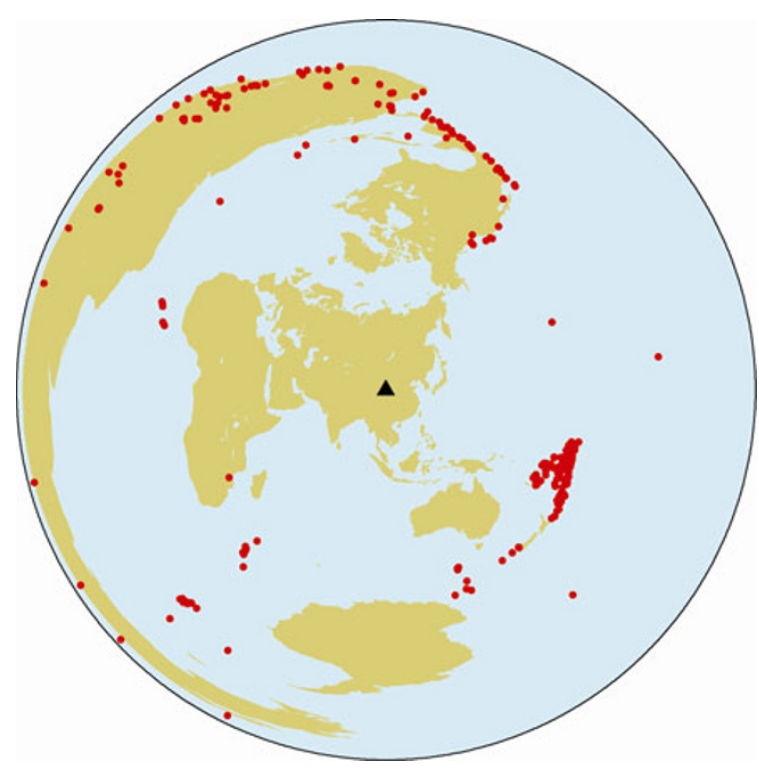

Figure 2 Location of the 405 teleseismic events used in this study. The black triangle represents the location of study region.

evaluated for many candidate values of fast direction and delay time (with respective increments of $1^{\circ}$ and $0.05 \mathrm{~s}$ ) to retrieve the pair of values that best removes influence of anisotropy. This method assumes that anisotropy is located at a single horizontal layer.
Individual results have been sorted in two categories (good and null), which were retained for interpretation. Measurements producing similar pulse shapes and linear particle motion after correction along with fairly small error ellipses were rated as "good", while a null measurement does not show any energy on the transverse component associated with the arrival of the core phase of interest on the radial component; this may be due either to an absence of anisotropy or to an initial polarization of the incoming shear wave parallel or orthogonal to the fast anisotropic direction. Figure 3 gives examples of waveform splitting at station XAN for event 2002-10-25.

To increase the robustness of the results compared to the analysis of single events, we have used the method of Wolfe and Silver (1998) to compute global solutions. This method simultaneously processes multiple events, at a single station, by normalizing and summing individual error surfaces. For those stations showing either no correlation between backazimuthal variations or splitting parameters that are more complex than the splitting predictions for a single anisotropic layer with a vertical symmetry axis, global solutions have been computed. 

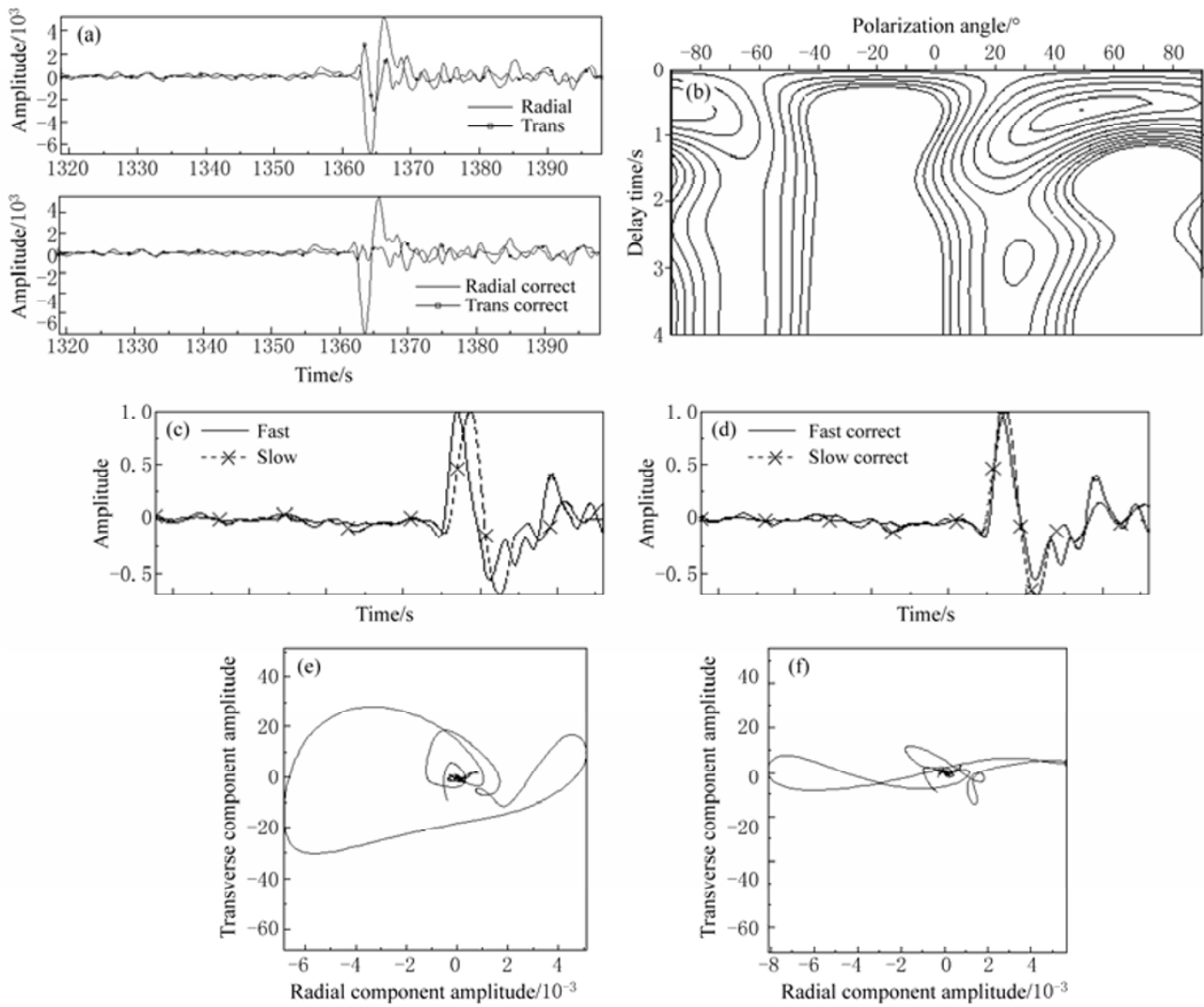

Figure 3 Example of shear wave splitting at station XAN for event 2002-10-25. (a) Initial radial and transverse components with the anisotropy (note the energy on the transverse component) and with the anisotropy removed (no more energy on the transverse component). (b) Contour plot of energy on the transverse component as a function of the delay time and the polarization angle of the fast split shear wave. Double contours represent the $95 \%$ confidence interval. (c) Uncorrected and (d) corrected for the best calculated delay time. Overplot of the fast (solid) and slow (dashed with cross) components of the split shear waves. Particle motions in the horizontal plane are shown below, also (e) uncorrected and (f) corrected from the anisotropy. Note that the elliptical particle motion is well linearized when the anisotropy is corrected.

\section{Results}

Significant shear wave splitting results were observed at 104 stations and only null results were obtained at 15 stations. The azimuth of the fast split shear wave together with the delay time of the non-null measurements for each station is plotted in Figure 4. Small to large values of delay time $(0.4-2.0 \mathrm{~s})$ are found, indicating ubiquitous anisotropic structure beneath the stations. In a first-order approximation, the high-quality measurements show little scattering at most stations, suggesting homogeneous mantle structures beneath the stations. However, a few stations (AAK, GTA, GUL, KKAR, ST28, ULN and WUS) show strong dispersion in the anisotropy parameters that could result from either several layers of anisotropy, from inclined anisotropic structures or from lateral variations in the upper mantle structure. We have obtained many null results due to the fact that the majority of events used lie in Tonga or adjacent regions (Figure 2) with backazimuth either parallel or perpendicular to the average fast direction at certain stations.

In order to best control the final results, we determined the mean value characterizing the anisotropy at each station. The averaged splitting parameters are shown in Figure 5. Figure 5 shows that the splitting observations are characterized by apparent diversity of anisotropy pattern in adjacent tectonic domains, including the Tianshan orogenic belt, Tibetan plateau, the Yangtze craton, the North China craton and northeastern region.

\subsection{The Tianshan orogenic belt}

We have 13 stations in Tianshan orogenic belt. Measurement results show that the fast directions in the west are NE-SW and gradually turn into E-W in the east. Delay time varies in a range from $0.65 \mathrm{~s}$ to $1.58 \mathrm{~s}$ with 


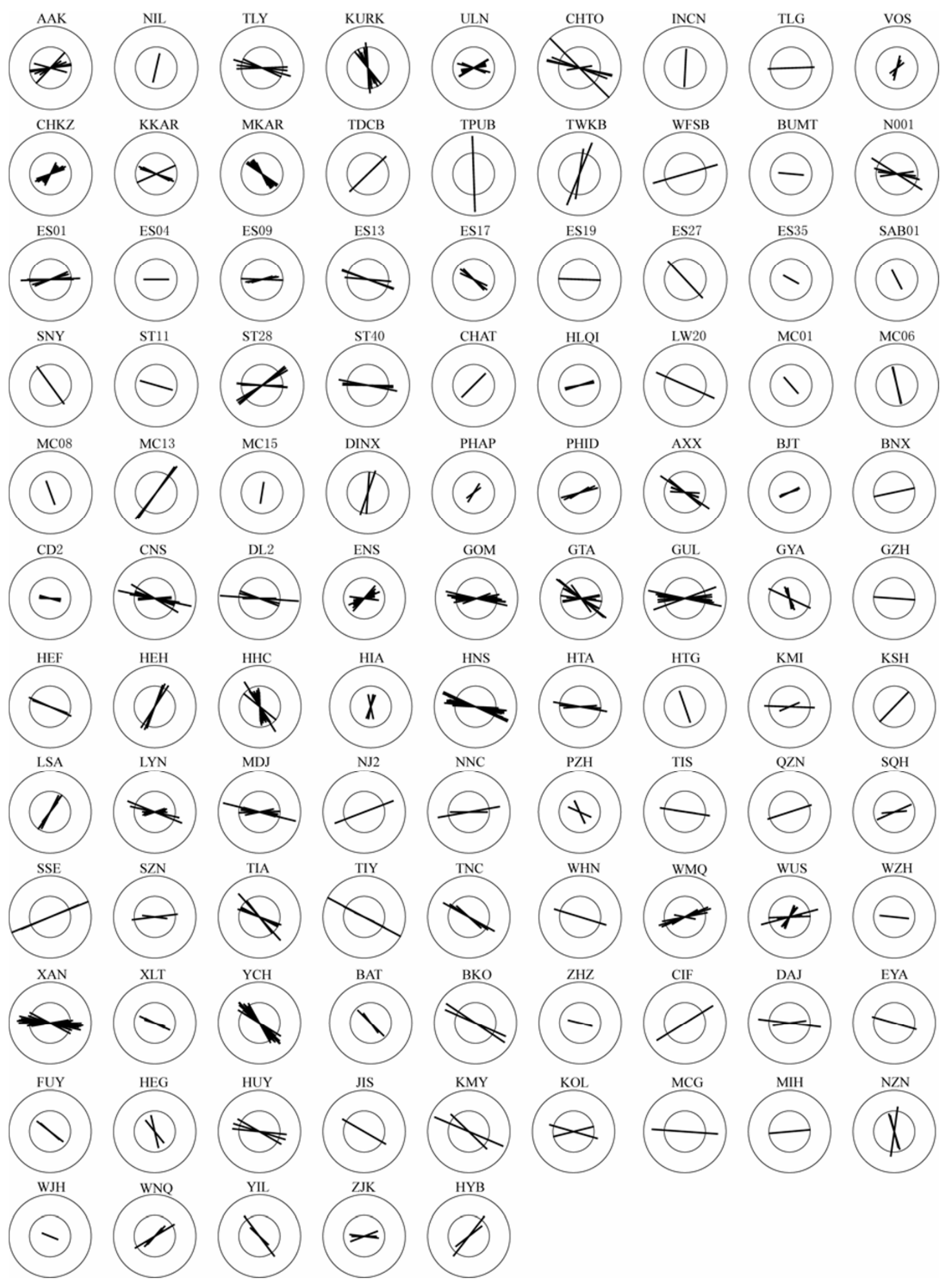

Figure 4 Summary of non-null measurements. For each station, individual splitting parameters are presented by black lines. Each circle represents $1 \mathrm{~s}$ of delay. It is important to note that this representation only plot the best parameters found by the program in the $95 \%$ confidence area. Some apparent scattering and inconsistency in the results (at AAK for instance) are, in fact, fully consistent considering this confidence interval. 


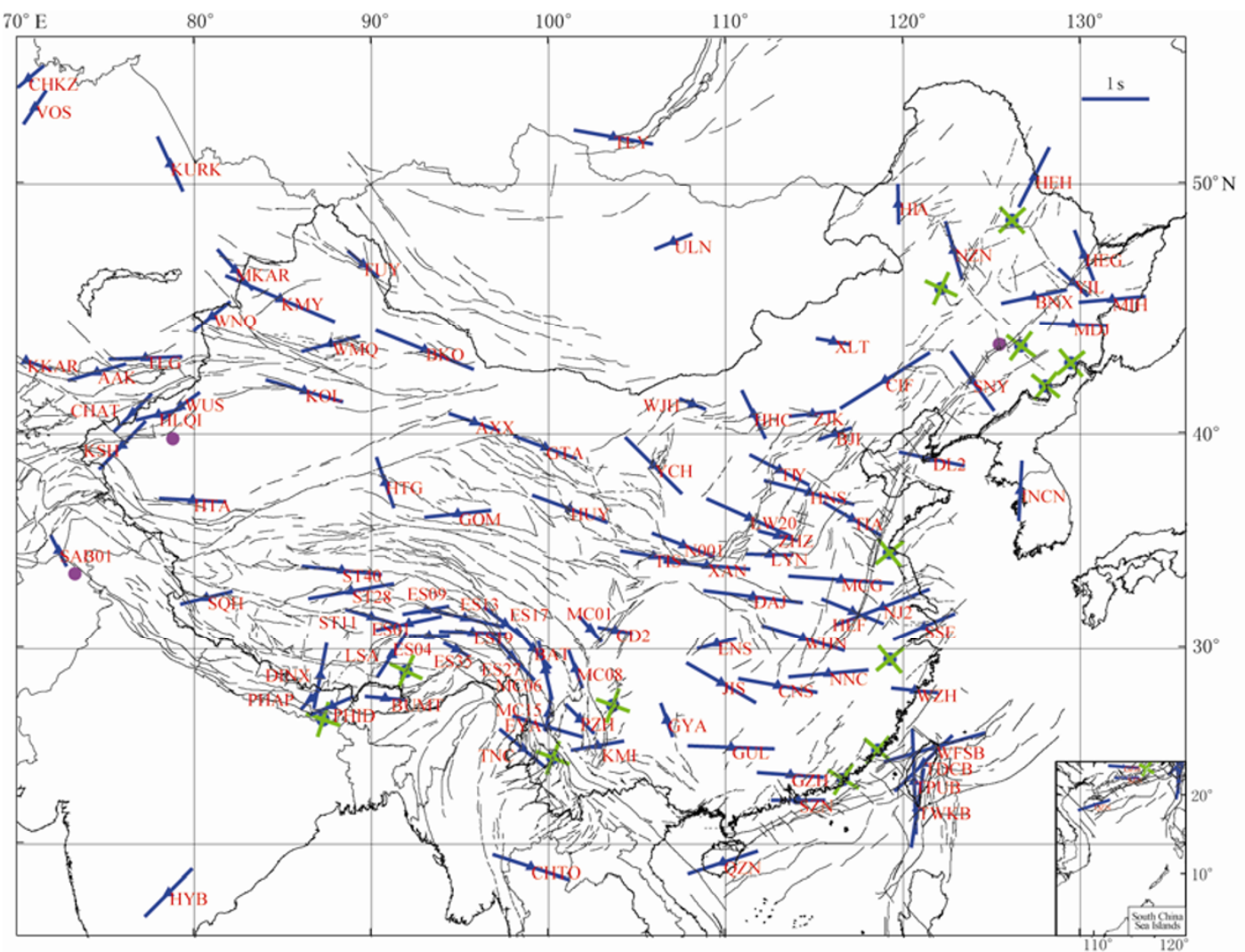

Figure 5 Map of the average splitting results calculated from individual measurements. Blue triangles denote stations with clear splitting. Orientation and length of blue bars indicate fast polarization direction and splitting delay time, respectively. Green dots with two orthogonal lines represent the absence of splitting from one back azimuth or two orthogonal back azimuths. Splitting at these stations is possible if the fast direction lies along either of the two directions. Purple dots denote the absence of splitting from at least two non-orthogonal backazimuths.

average value of $0.97 \mathrm{~s}$. At station $\mathrm{BCH}$, data from five earthquakes were analyzed and all yielded null results. These five earthquakes were at backazimuths of $\mathrm{N} 43^{\circ} \mathrm{E}$, $\mathrm{N} 40^{\circ} \mathrm{E}, \mathrm{N} 128^{\circ} \mathrm{E}, \mathrm{N} 133^{\circ} \mathrm{E}$ and $\mathrm{N} 126^{\circ} \mathrm{E}$, respectively, consistent with a NE-SW fast direction observed at the nearby stations KSH, HLQI and WUS. Similar anisotropic pattern have already been reported by $\mathrm{Li}$ and Chen (2006) for this area.

\subsection{The Tibetan plateau}

Shear wave splitting was observed at 20 stations in the Tibetan plateau. In northern Tibet, large polarization anisotropy has been observed. Homogeneously oriented fast split directions trend $\mathrm{N} 285^{\circ} \mathrm{E}$ at station AXX, GTA and HUY. Fast directions at station HTG and GOM are parallel to the trend of large scale strike-slip faults like Kunlun fault. Ding and Zeng (1996) found similar results. In central Tibet, the nine temporary seismic stations from INDEPTH III and Namjagbarwa networks are characterized by consistent fast directions trending EW and moderate delay time ( $0.6 \mathrm{~s}$ to $1.0 \mathrm{~s})$. Huang et al.
(2000) and Sol et al. (2007) also reported similar splitting results. In south Tibet, negligible polarization seismic anisotropy has been obtained. The observed direction of anisotropy at station BUMT in Bhutan is subparallel to the strike of the Himalaya. At station PHAP, PHID, DINX and LSA, fast directions are oriented mainly in the NE direction, close to the absolute plate motion direction of the Indian plate, in a no-net reference frame $\sim 41^{\circ}$ (DeMets et al., 1994). At station LSA, McNamara et al. (1994) reported null results; Sandvol et al. (1997) found a number of no split SKS phase and one clear split SKKS phase with the fast direction of N2 $8^{\circ}$ E. At station PHAP, Singh et al. (2007) observed an E-W fast direction. Fu et al. (2008) obtained the similar NE-trending fast direction in this area. In southeast margin, clear anisotropy has been observed but with different pattern from north to south. The fast direction changes from N-S in north to E-W in Yunnan, which is consistent with that from Chang et al. (2006). The fast directions of split shear waves vary smoothly in orienta- 
tion from NE-SW, E-W to NW-SE from south to north. There is a clockwise rotation of fast directions around the eastern Himalayas syntax.

\subsection{The Yangtze craton}

Large values of delay time are observed in this region with an average of $\sim 1.3 \mathrm{~s}$. The largest delay time up to $2.0 \mathrm{~s}$ is obtained at station GUL located near the east margin of Chinese mainland. The fast splitting direction shows good consistency trending NW or WNW. At station XAJ, SHT and QZH, only null results were obtained. Most of our results are consistent with those of Luo et al. (2004), with some exceptions, like stations GYA and WHN. Zhao et al. (2007) found the splitting direction of NE or ENE, approximately perpendicular to our NW or WNW fast direction. However, at station NJ2 and SSE, our fast directions are the same as those of Zhao et al. (2007).

\subsection{The North China craton}

Shear wave splitting was observed at 30 stations in the North China craton. Each station has 3-14 individual measurements. The fast directions are oriented NW-SE at most of stations. It is in good agreement with the NW-SE fast directions observed in the Yangtze craton. However, the NE-trending fast directions which are along the strike of regional tectonic features (Ma et al., 1989) and much smaller delay time around $0.6 \mathrm{~s}$ were observed at station $\mathrm{ZJK}$ and BJI. Our fast directions are at high angle relative to those observed by Zhao et al. (2007) except at station BJI. Station LYG just has null results.

\subsection{The northeastern China}

The fast splitting directions show a complex pattern in this region. Null results as well as non-null results were obtained at most of stations. Station MDJ, $\mathrm{MIH}$ and BNX give consistent fast directions trending E-W. Fast directions at station SNY, YIL, HEG, NZN and HIA are NW-trending. There are five stations which just have null results. At station XLT, lots of events produced statistically consistent results for both fast direction $\mathrm{N} 88^{\circ} \mathrm{E}$ and delay time $0.4 \mathrm{~s}$. In the vicinity of XLT, the Late Paleozoic orogenic belt has a nearly E-W strike (Ma et al., 1989). The fast direction agrees well with the strike of this orogenic belt. There is a large angular difference between our result and that from Liu et al. (2008) for station XLT and HIA.

Interestingly, all stations which only exhibit null results locate at the margin of Chinese mainland (Figure $5)$. This peculiar feature of anisotropy may reflect complex structure beneath those stations. One possibility is a multilayered anisotropic model. However, most of those stations just have a single, or a small number of null measurements with backazimuths parallel or perpendicular to each other. Data processed at those stations correspond to a time span of recording of only one year. We can not rule out the multilayered anisotropy as a cause of the observed nulls. No definite conclusion can be highlighted in view of only few measurements because splitting parameters can be correctly interpreted only in the context of a large number of measurements covering a long time span and/or a wide range of backazimuths.

\section{Discussion}

The main challenge in studying core-refracted shear waves is the lack of vertical resolution. The anisotropy measured at the surface has been acquired on the way from the CMB to the surface; the splitting parameters therefore represent an integrated measurement and we need to consider whether a lithospheric or an asthenospheric source, or a combination of both, may account for the observed anisotropy. We take the opportunity of the dense geodetic measurements available in China to refine this discussion.

\subsection{Sublithospheric mantle flow model}

In the case of a decoupling between a "flat" lithospheric plate and the underlying upper mantle, simple asthenospheric flow would lead to splitting parameters very coherent over large geological domains that differ in both age and structure: the orientation of the polarization plane of the fast shear wave would be parallel to the absolute plate motion (APM), and the amplitude of the delay time would be rather constant in each domain. In China, the recent HS3-Nuvel 1A plate motion model relative to the hotspot reference frame (Gripp and Gordon, 2002) indicates that the Eurasian plate moves towards an azimuth of $280^{\circ}$ at a velocity of $2 \mathrm{~cm} / \mathrm{a}$. At the Chinese mainland scale however, considering the results as a whole, the directions of anisotropy obtained from shear wave splitting appear to be very scattered. The SKS splitting directions we observe across the Yangtze craton and in North China craton are relatively close to this azimuth. Further west, the fast azimuth across the Tianshan and Tibet is at the high angle relative to the APM. In the present study, we can not highlight any simple relationship between the orientations of the polarization plane of the fast shear wave and the APM of China. The absolute plate motion can explain 
some observations, but some large angular differences observed in several areas suggest that more complex anisotropic structures are probably involved.

Following one school of thought (Vinnik et al., 1992; Bormann et al., 1996), the topography of the lithosphere-asthenosphere boundary may obviously influence the asthenospheric flow induced by the APM and/or the India-Asia collision, the subduction of the Pacific plate and Philippine plate and may locally or regionally explain angular differences between fast split wave and APM directions. Results from tomography of the Chinese mainland suggest that the thermal base of the cratonic roots of Tarim, Ordos and Sichuan basins extend down to more than $200 \mathrm{~km}$ depth (Wang et al., 2003; Sun et al., 2006), whereas the lithosphere beneath eastern China is likely less than $100 \mathrm{~km}$ thick (An and Shi, 2006; Pei et al., 2007). The mantle beneath eastern China is characterized by low velocities between $80 \mathrm{~km}$ and $200 \mathrm{~km}$, suggesting the presence of buoyant material in the mantle sustains the lithosphere (Pei et al., 2007). The primary effect that the thick three cratonic keels may have on the asthenospheric flow induced by the India-Asia collision is to deviate it from $\mathrm{NE}$ and make it wrap around the cratons. These rotations are indeed observed, suggesting that at least part of our observations could have an asthenospheric origin related to the plate motion and collision.

\subsection{Lithospheric deformation model}

Due to the limited amount of reliable measurements performed at each station, no direct correlation is observed between the measured orientation of the fast shear waves and the mapped superficial structures. It is therefore impossible to assert that anisotropy frozen in the lithosphere is the main source of anisotropy.

However, with a closer look at the data, some correlations can be seen, especially (1) in the Tianshan orogenic belt, and (2) in the Tibetan plateau. In the Tianshan orogenic belt, the directions of anisotropy show various orientations. We can divide the results into two different groups with respect to the surface geology, from south to north. In the southern part, at those stations (KSH, CHAT, HLQI, WUS and KOL) located along the boundary between Tianshan orogenic belt and the Tarim basin, fast directions just follow the strike of the orogenic belt and show a clockwise rotation. In the northern part, the fast anisotropic direction is oriented $\mathrm{N} 290^{\circ} \mathrm{E}$ at station $\mathrm{KKAR}$, while it turns into $\mathrm{N} 80^{\circ}-40^{\circ} \mathrm{E}$ at station AAK, TLG, WMQ, and WNQ. The directions of anisotropy at those stations are subparallel to the structural trend of the Tianshan orogen. In the Tibetan plateau, the fast direction displays apparent spatial variations. The polarization directions reveal a pronounced transition from primarily $\mathrm{NE}$ in the south to mostly east-west orientations in center to NW in the north. In central and eastern Tibet, the fast splitting direction is parallel to the major strike-slip faults and Bangong-Nujiang suture. In northern Tibet, there is a conspicuous correlation between the orientation of the fast split shear wave polarization plane and the structural trend of Kunlun orogen and Kunlun fault zones.

The short scale variations in fast directions in Tianshan orogenic belt and Tibet argue for shallow variations in the lithospheric fabric. The fast direction of anisotropy is parallel to the strike direction of the lithospheric units, of the ancient accretionary belts and of the suture zones, we therefore suggest that part of the observed anisotropy resulted from the lithosphere formation and deformation and remained frozen since the $\mathrm{Pa}$ leozoic and Mesozoic times is still visible.

\subsection{Combination of sublitospheric mantle flow and lithospheric deformation model}

As shown above, neither the end-member models of lithospheric nor sublithospheric mantle flow layer anisotropy can completely satisfy the patterns of shear wave splitting in China, leading us to favor the existence of anisotropy in both the lithospheric and sublithospheric mantle. Patterns of fast directions for a few regions reduce the possibility that splitting is controlled completely by sublithospheric mantle flow. A component of lithospheric anisotropy must exist in western China and is particularly required in northeastern region that exhibit strong variations in fast directions over short spatial scales. On the other hand, the correlation in fast directions between our mantle flow model and the observed values for eastern China indicates that mantle flow can play a significant role in the generation of anisotropy.

However, the splitting observations may be easily explained by a model in which shear wave splitting patterns are controlled by both sublithospheric mantle flow and anisotropy in the lithosphere. The anisotropy is likely related to several processes, the effects of which may be added together: the frozen lithospheric deformation inherited from its Paleozoic built up, a sublithospheric mantle flow induced by the plate motion, and the pervasive deformation induced by the present day compression and the deep accommodation of the India-Asia collision. These hypotheses are compatible 
with the lithosphere thickness derived from tomographic observations but also with the petrological and petrophysical data.

Together with the tomographic images (Pei et al., 2007), our shear wave splitting measurements evidence the major influence of India-Asia collision and subduction in the western Pacific on the large-scale behavior and deformation of the lithosphere and asthenosphere. Based upon shear wave splitting observations in this study, we propose a model for the asthenospheric flow in China (Figure 6). Since the Indian plate is subducting northward whereas the Myanmar microplate descends eastward beneath the Eurasian plate ( $\mathrm{Ni}$ et al., 1989), large fragments of Eurasian lithosphere and asthenosphere were extruded out of central Tibet because of the old, cold and strong Siberian platform in the north, from the Bangong-Nujiang suture region toward southern China, northern Indochina eastward and Ladakh, western Pakistan westward, respectively. To the east, the eastward moving upper mantle flow is diverted northeast and southeast around the Ordos plateau and the Sichuan basin. Marked by fast $\mathrm{P}$-wave propagation to at least $250 \mathrm{~km}$ depth, those two basins appears to be deeply rooted, mechanically strong units underlain by craton-like lithosphere. These two cratons influence the pattern of mantle flow deflected by deep roots. In North China and Yangtze cratons, the asthenospheric flow

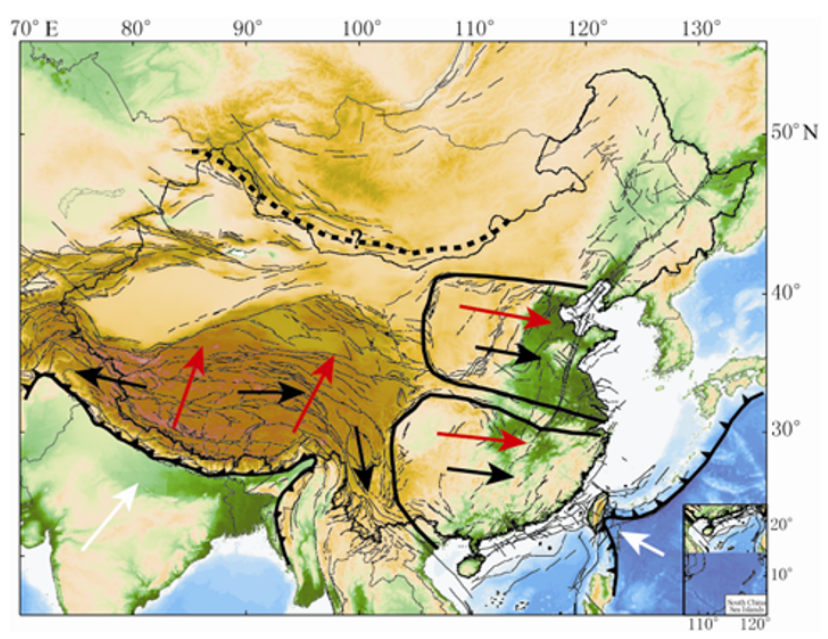

Figure 6 An interpretive asthenospheric flow model in China based upon our shear wave splitting measurements. Black arrows denote the asthenospheric flow direction inferred from fast directions. Red arrows show the surface deformation direction inferred from GPS measurements. The absolute plate motion (APM) calculated from HS3-Nuvel1A model (Gripp and Gordon, 2002) for the Indian plate and western Pacific plate are indicated by the white arrows. moves in southeast direction. The southeastward asthenospheric flow induced by eastward extrusion of Tibet and the trench rollback in the western Pacific resulted in large scale extension in eastern China.

\subsection{Coupling between the crust and mantle}

Interpretation of upper mantle seismic anisotropy in such a tectonically active area requires us to discuss the large scale signal observed from shear wave splitting measurements that provides information on the deep Earth deformation with respect to the present day tectonic processes observed at the surface. We can obtain some constraints on mechanical crust-mantle coupling for China, by comparing the observed surface deformation field inferred from GPS and Quaternary fault slip rate data, with the mantle deformation field inferred from several shear wave splitting data sets.

The tectonics of western China is dominated by subduction of Indian lithosphere beneath Eurasian lithosphere, thickening of Tibetan crust, and eastward extrusion of Tibetan lithosphere toward southern China and northern Indochina (England and Houseman, 1989; Tapponnier et al., 2001; Royden et al., 2008). Contrastingly, large NE-trending strike-slip fault zones and extensional basin system characterize active tectonics in eastern China (e.g., Charvet et al., 1996; Gilder et al., 1996; Li, 2000; Wang et al., 2005). At the plate-scale, geodetical observations show that the India-Eurasia collision is accommodated by intracontinental deformation, dominated by block motions along major strike-slip faults and internal strain within lithospheric blocks, except in high elevation areas (Calais et al., 2006; Thatcher, 2007). Compilation of the geodetic measurements performed in Asia by Calais et al. (2006) and the velocity filed modeled from GPS velocities and Quaternary fault slip rates (Flesch et al., 2001, 2005) both clearly evidence that the accommodation of the $4 \mathrm{~cm} / \mathrm{a}$ convergence of India relative to Eurasia is gradually absorbed northward and tends towards zero on the Siberian platform. The GPS velocities are, relative to stable Eurasia, on the order of $30 \mathrm{~mm} / \mathrm{a}$ in southern and central Tibet, less than $10 \mathrm{~mm} / \mathrm{a}$ in the North China and Tianshan area.

The trend of fast split wave direction close to the GPS velocity vectors in eastern China (Figure 7) suggests a relation between mantle flow and the surface crustal block motions that can be summarized in a model of crustal blocks escaping consistently with the mantle deformation. Such regime of transpressive deformation may orient olivine [001] axis parallel to the block escape. There is a strong coupling between crust 
and mantle beneath eastern China. However, this pattern cannot be extrapolated to western China since GPS and anisotropy observations are clearly oriented at high angle from each other (Figure 7). In this area, fast direction is indeed oriented E-W to WNW-ESE in central and northern Tibet and NE in Tianshan whereas the GPS vectors in the Eurasia reference frame trend NE in central and northern Tibet and NW in Tianshan (Wang et al., 2003), i.e., close to the regional compression direction (e.g., Petit et al., 1996). GPS vectors and fast anisotropic directions are therefore normal to each other in western China, arguing for complete crust-mantle decoupling.

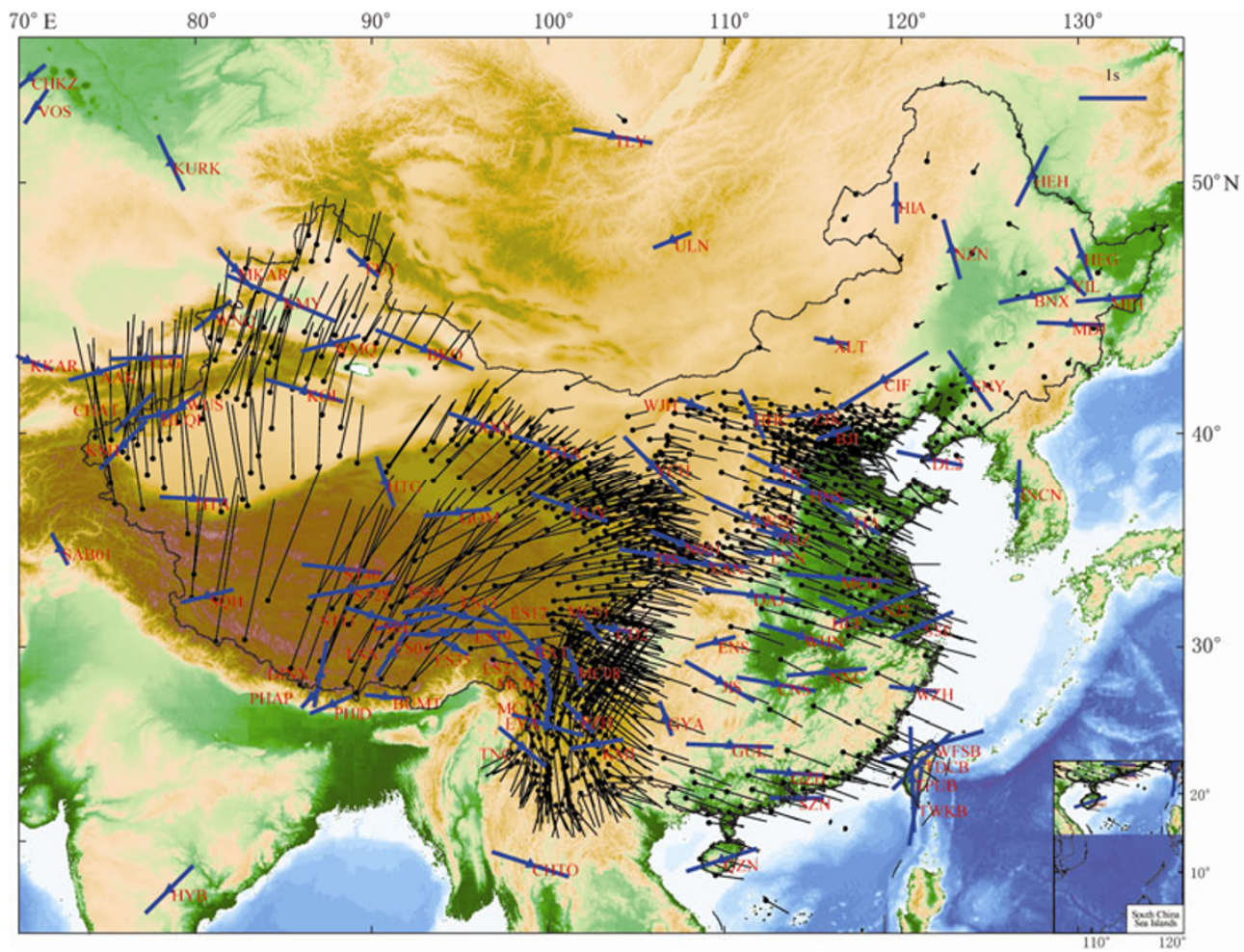

Figure 7 Topographic map of China and surrounding areas showing the mean shear wave splitting measurements available in the region, together with the GPS vectors from Wang et al. (2003). Black lines indicate the velocity field with respect to a fixed Eurasian plate. The blue line length scales the delay time, while the orientation indicates the fast polarization direction. The solid black circles represent the GPS station. The solid blue triangles represent the seismic station.

As we show, there is a distinct change in the kinematic behavior of the crust and mantle between western and eastern China (Figure 6). In the case of Tibet in western China, the upper mantle moves in E-W direction while the crust is moving in N-S. The crust and mantle deform independently. This decoupling behavior is consistent with the popular "jelly-sandwich" rheology (Molnar and Lyon-Caen, 1988), and thus supports behavior such as large-scale crustal flow (Beaumont et al., 2001; Shapiro et al., 2004; Liang et al., 2008). In contrast, in North China and Yangtze craton, the surface and upper mantle both move in southeast direction. The coherence of the crustal and mantle deformation fields shows that both sources of stress, topographically induced stresses and collision boundary conditions, are transmitted throughout the depth range of the litho- sphere. This transmission of stresses argues for a mechanically coupled lithosphere in eastern China.

\section{Conclusions}

Shear wave splitting parameters from stations of the CDSN and some temporary seismic networks show clear patterns of splitting across the Chinese mainland. Fast directions for stations located in eastern China are roughly parallel to the absolute plate motion, while fast directions for the western part exhibit rapid variations but are sub-parallel to the trend of orogen and strike-slip fault. At those stations in Tianshan and Tibet, the overall parallelism of the fast directions with the trend of the lithospheric structures suggests active mantle deformation at the scale of the lithosphere. In North and South China cratons, the distribution of these strong anisot- 
ropies is not along the present day major lithospheric structures (sutures and lithospheric faults), suggesting that part of the anisotropy may lie in the sublithospheric mantle. These observations led us to propose that the observed pattern of shear wave splitting in China originates from both lithospheric and asthenospheric deformation. The lithospheric anisotropy likely results from long-lasting geological evolution along active margins but also from the recent and present day deformation of the China lithosphere along the large scale strike-slip faults and under the regional NNE-SSW compression regime. The deeper anisotropy is likely related to the asthenospheric flow induced by the relative motion of the present day Eurasian plate and the deep mantle circulation.

Based upon seismic anisotropy pattern we observed, we infer that the sublithospheric flow induced by the India-Asia collision escapes toward the east from Tibet, deflects around the deep roots of Ordos plateau and Sichuan basin and moves beneath North China craton and Yangtze craton in southeast direction. This flow model appears to be controlled by the presence of Siberian craton in the north that acted as an undeformable core of the continent.

We have obtained constraints on mechanical crustmantle coupling for China by comparing the observed surface deformation field inferred from GPS with the mantle deformation field inferred from shear wave splitting data sets. The contrast between the behavior of western and eastern China is striking. The inferred change from decoupled to strongly coupled lithosphere suggests that there is a profound lateral transition in the strength profile of the lithosphere over the China region.

Acknowledgements The authors would like to thank Eric Sandvol for his valuable help in data processing and SKS signal analysis. Figures are produced by the GMT tool (Wessel and Smith, 1998). This study was supported by National Natural Science Foundation of China (Nos. 40520120222, 40125011, and 40521002) and Peking University.

\section{References}

An M J and Shi Y L (2006). Lithospheric thickness of the Chinese continent. Phys Earth Planet Int 159: 257-266.

Argand E (1924). La tectonique de l'Asie. Int Geol Congr Rep Sess 13: 170-372.

Beaumont C, Jamieson R A, Nguyen M H and Lee B (2001). Himalayan tectonics explained by extrusion of a low viscosity crustal channel coupled to focused surface denudation. Nature
414: 738-742.

Bormann P G, Gruenthal G, Kind R and Montag H (1996). Upper mantle anisotropy underneath central Europe: Effect of absolute plate motion and lithosphere-asthenosphere boundary topography? J Geodyn 22: 11-32.

Calais E, Dong L, Wang M, Shen Z and Vergnolle M (2006). Continental deformation in Asia from a combined GPS solution. Geophys Res Lett 33, doi: 10.1029/2006GL028433.

Chang L, Wang C and Ding Z (2006). A study on SKS splitting beneath the Yunnan region. Chinese J Geophys 49: 197-204.

Charvet J, Shu L S, Shi Y S, Guo L Z and Faure M (1996). The building of south China: Collision of Yangzi and Cathaysia blocks, problems and tentative answers. J Southeast Asian Sci 13: 223-235.

DeMets C, Gordon R G, Argus D F and Stein S (1994). Effect of recent revisions to the geomagnetic reversal time scale on estimate of current plate motions. Geophys Res Lett 21: 2 1912194.

Dewey J and Burke K (1973). Tibetan, Variscan and Precambrian basement reactivation: Products of continental collision. $J$ Geol 81: 683-692.

Ding Z and Zeng R (1996). Observation and study of shear wave anisotropy in Tibetan Plateau. Chinese J Geophys 39: 188-195.

England P and Houseman G (1986). Finite strain calculations of continental deformation: 2. Comparison with the India-Asia collision zone. J Geophys Res 91: 3 664-3 676.

England P and Houseman G (1989). Extension during continental convergence, with application to the Tibetan Plateau. $J$ Geophys Res 94: 17 561-17 579.

Fan W and Menzies M A (1992). Destruction of aged lower lithosphere and accretion of asthenosphere mantle beneath eastern China. Geotect Metall 16: 171-180.

Flesch L M, Haines A J and Holt W E (2001). Dynamics of the India-Eurasia collision zone. J Geophys Res 106: 16 43516460.

Flesch L M, Holt W E, Silver P G, Stephenson M, Wang C and Chan W W (2005). Constraining the extent of crust-mantle coupling in central Asia using GPS, geologic, and shear wave splitting data. Earth Planet Sci Lett 238: 248-268.

Fu Y V, Chen Y J, Li A, Tang Y, Liang X, Ye G and Zhou S (2008). Indian mantle corner flow at southern Tibet revealed by shear wave splitting measurements. Geophys Res Lett 35(2): L02308.

Gilder S A, Gill J, Coe R S, Zhao X X, Liu Z W, Wang G X, Yuan K R, Liu W L, Kuang G D and Wu H R (1996). Isotropic and paleomagnetic constraints on the Mesozoic tectonic evolution of south China. J Geophys Res 101: 16 137-16 154.

Gripp A E and Gordon R G (2002). Young tracks of hotspots and current plate velocities. Geophys J Int 150: 321-364.

Houseman G A, McKenzie D P and Molnar P (1981). Convective instability of a thickened boundary layer and its relevance for the thermal evolution of continental convergent belts. $J$ Geophys Res 86: 6 115-6 132.

Huang W, Ni J F, Tilmann F, Nelson D, Guo J, Zhao W, Mechie J, Kind R, Saul J, Rapine R and Hearn T M (2000). Seismic polarization anisotropy beneath the central Tibetan Plateau. $J$ 
Geophys Res 105(B12): 27 979-27 989.

Li A and Chen C Z (2006). Shear wave splitting beneath the central Tien Shan and tectonic implications. Geophys Res Lett 33: L22303.

Li X H (2000). Cretaceous magmatism and lithospheric extension in Southeast China. J Southeast Asian Sci 18: 293-305.

Liang X, Zhou S, Chen Y J, Jin G, Xiao L, Liu P, Fu Y, Tang Y, Lou $X$ and Ning J (2008). Earthquake distribution in southern Tibet and its tectonic implications. J Geophys Res 113: B12409.

Liu G (1987). The Cenozoic rift system of the North China Plain and the deep internal process. Tectonophysics 133: 277-285.

Liu G D, Hao T Y and Liu Y K (1997). The macroscopically geotectonic framework of China and its relationship with mineral source: Knowledge from the geophysical data. Chinese Science Bulletin 42: 113-118 (in Chinese with English abstract).

Liu K H, Gao S S, Gao Y and Wu J (2008). Shear wave splitting and mantle flow associated with the deflected Pacific slab beneath northeast Asia. J Geophys Res 113: B01305.

Luo Y, Huang Z X, Peng Y J and Zheng Y J (2004). A study on SKS wave splitting beneath the China mainland and adjacent regions. Chinese J Geophys 47: 812-821 (in Chinese with English abstract).

Ma X, Zhang J and Lao Q (1989). Lithospheric Dynamics Atlas of China. China Cartogr. Publ. House, Beijing, 252 (in Chinese).

McNamara D E, Owens T J, Silver P G and Wu F T (1994). Shear wave splitting beneath the Tibetan Plateau. J Geophys Res 99: $13655-13665$.

Menzies M A, Fan W M and Zhang M (1993). Palaeozoic and Cenozoic lithoprobes and the loss of $>120 \mathrm{~km}$ of $\mathrm{Ar}-$ cheanlithosphere, Sino-Korean craton, China. In: Prichard H M, Alabaster T, Harris N B W and Neary C R eds. Magmatic Processes and Plate Tectonics. Geological Society Special Publication No. 76, London, 71-78.

Molnar P (1988). A review of geophysical constraints on the deep structure of the Tibetan Plateau, the Himalaya and the Karakorum, and their tectonic implications. Philos Trans $R$ Soc London 326: 33-88.

Molnar P and Lyon-Caen H (1988). Some simple physical aspects of the support, structure, and evolution of mountain belts. Geologic Society of America Special Paper 218: 179-207.

Molnar P, England P and Martinod J (1993). Mantle dynamics, uplift of the Tibetan Plateau, and the Indian monsoon. Rev Geophys 31: 357-396.

Ni J and Barazangi M (1984). Seismotectonics of the Himalayan collision zone: Geometry of the underthrusting Indian plate beneath the Himalaya. J Geophys Res 89: 1 147-1 163.

Ni J, Guzmanspeziale M, Bevis M, Holt W E, Wallace T C and Seager W R (1989). Accretionary tectonics of Burma and the 3-dimensional geometry of the Burma subduction zone. Geology 17: 68-71.

Niu Y L (2005). Generation and evolution of basaltic magmas: Some basic concepts and a new view on the origin of Mesozoic-Cenozoic basaltic volcanism in eastern China. Geol $J$ China Univ 11: 9-46.

Pei S, Zhao J, Sun Y, Xu Z, Wang S, Liu H, Rowe C A, Toksöz M $N$ and Gao X (2007). Upper mantle seismic velocities and anisotropy in China determined through Pn and Sn tomography. J Geophys Res 112, doi: 10.1029/2006JB004409.

Petit C, Déverchere J, Houdry F, San'kov V, Melnkova V and Delvaux D (1996). Present day stress field changes along the Baikal rift and tectonic implications. Tectonics 15: 1 1711191.

Powell C and Conaghan P (1973). Plate tectonics and the Himalayas. Earth Planet Sci Lett 20: 1-12.

Royden L H, Burchfiel B C and van der Hilst R D (2008). The geological evolution of the Tibetan plateau. Science 321: $1054-1058$.

Sandvol E, Ni J, Kind R and Zhao W (1997). Seismic anisotropy beneath the southern Himalaya-Tibet collision zone. $J$ Geophys Res 102: 17 813-17 823.

Shapiro N M, Ritzwoller M H, Molnar P and Levin V (2004). Thinning and flow of Tibetan crust constrained by seismic anisotropy. Science 305: 233-236.

Silver P G and Chan W W (1991). Shear wave splitting and subcontinental mantle deformation. J Geophys Res 96: 16 42916454.

Singh A, Kumar M R and Raju P S (2007). Mantle deformation in Sikkim and adjoining Himalaya: Evidences for a complex flow pattern. Physics Earth Planet Inter 164: 232-241.

Sol S, Meltzer A, Bürgmann R, van der Hilst R D, King R, Chen Z, Koons P O, Lev E, Liu Y, Zeitler P K, Zhang X, Zhang J and Zurek B (2007). Geodynamics of the southeastern Tibetan Plateau from seismic anisotropy and geodesy. Geology 35(6): 563-566.

Sun Y, Li X, Kuleli S, Morgan F D and Toksöz M N (2006). Adaptive moving window method for 3D P-velocity tomography tomography and its application in China. Bull Seismol Soc Am 94: 740-746.

Tapponnier P, Xu Z Q, Roger F, Meyer B, Arnaud N, Wittlinger G and Yang J (2001). Oblique stepwise rise and growth of the Tibet plateau. Science 294: 1 671-1 677.

Thatcher W (2007). Microplate model for the present day deformation of Tibet. $J$ Geophys Res 112, doi: 10.1029/2005JB004244.

Vinnik L P, Makeyeva L I, Milev A and Usenko A Y (1992). Global patterns of azimuthal anisotropy and deformations in the continental mantle. Geophys J Int 111: 433-437.

Wang C, Chan W W and Mooney W D (2003). Three-dimensional velocity structure of crust and upper mantle in southwestern China and its tectonic implications. $J$ Geophys Res 108: $2442-2458$.

Wang M, Shen Z, Niu Z, Zhang Z, Sun H, Gan W, Wang Q and Ren Q (2003). Model of crustal motions and active blocks of present day China. Science in China (Series D) 33: 21-32.

Wang Q, Li J W, Jian P, Zhao Z H, Xiong X L, Bao Z W, Xu J F, Li C F and Ma J L (2005). Alkaline syenites in eastern Cathaysia (South China): Link to Permian-Triassic transtension. Earth Planet Sci Lett 230: 339-354.

Wessel P and Smith W H F (1998), New improved version of the Generic Mapping Tools released. EOS, Trans AGU 79: 579.

Wolfe C J and Silver P G (1998). Seismic anisotropy of oceanic upper mantle: Shear wave splitting methodologies and observations. J Geophys Res 103: 749-771. 
Wu F Y, Lin J Q, Wilde S A, Zhang X O and Yang J H (2005). Nature and significance of the Early Cretaceous giant igneous event in eastern China. Earth Planet Sci Lett 233: 103-119.

Zhang M, Suddaby P, O'Reilly S Y, Norman M and Qiu J X (2000). Nature of the lithospheric mantle beneath the eastern part of the central Asian fold belt: Mantle xenolith evidence. Tectonophysics 328: 131-156.

Zhao L, Zheng T, Chen L and Tang Q (2007). Shear wave split- ting in eastern and central China: Implications for upper mantle deformation beneath continental margin. Physics Earth Planet Inter 162: 73-84.

Zhao W and Morgan W J (1987). Injection of Indian crust into Tibetan lower crust: A two-dimensional finite element model study. Tectonics 6: 505-514.

Zheng S and Gao S (1994). The azimuth anisotropy of lithosphere of continental China. Acta Seismologica Sinica 7: 553-561. 